\title{
Effects of Precipitation, Temperature and Wind in Alpine Areas on Backcountry Avalanche Accidents Reported in the Western Part of Austria within 1987- 2009
}

\section{Christian Pfeifer ( $\nabla$ christian.pfeifer@uibk.ac.at)}

Leopold Franzens Universität für Innsbruck: Universitat Innsbruck https://orcid.org/0000-0002-2258433X

\section{Peter Höller}

Leopold Franzens Universität für Innsbruck: Universitat Innsbruck

\section{Research Article}

Keywords: weather data, avalanche accidents, avalanche problems

Posted Date: July 23rd, 2021

DOl: https://doi.org/10.21203/rs.3.rs-588518/v1

License: (c) (1) This work is licensed under a Creative Commons Attribution 4.0 International License.

Read Full License 


\section{Effects of precipitation, temperature and wind in alpine areas on backcountry avalanche accidents reported in the western part of Austria within 1987-2009}

\section{Christian Pfeifer • Peter Höller}

7 Received: date / Accepted: date

8 Abstract In this article, we are going to investigate the effects of snow, rain, temperature and wind on the number of backcountry and off-piste avalanche accidents. The data base of our survey is restricted on the western part of Austria (federal states Tyrol and Vorarlberg) within the winter periods 1987/882008/09. We are able to stratify the daily data for municipalities in Tyrol and Vorarlberg.

Employing spatial kriging and hurdle models, we found a positive significant effect of the snow water equivalent measurement on avalanche accident counts (if we consider the running average over the past 3 days). The variables rain and temperature 1800 meter above sea level showed negative effects on the number of accident counts. In the case of the variable wind - ERA5 global reanalysis data turned out not to be reliable - we had a focus on the 3 avalanche accident hot spots of Austria St. Anton am Arlberg, Lech and Sölden observing wind data of the weather stations Galzig, Warth and Obergurgl. At least in the case of St. Anton and Lech, we found significant positive effects (daily velocity totals and west wind component) on the number of avalanche counts. Calculating the daily mean wind load showed a positive effect only in the case of St. Anton am Arlberg.

Finally, we tried to find conclusions in connection with 'avalanche problems' such as used by several avalanche information services only finding (beside 'new snow') some evidence for a 'spring scenario'.

29 Keywords weather data $\cdot$ avalanche accidents $\cdot$ avalanche problems

Christian Pfeifer

Institut für Statistik, Universität Innsbruck, A-6020 Innsbruck

Peter Höller

Bundesamt und Forschungszentrum für Wald, Institut für Naturgefahren, A-6020 Innsbruck 


\section{Introduction}

Beginning with the 1980s, the popularity of backcountry (and off-piste) skiing has increased considerably (Techel et al. 2016; Zweifel 2006).

In Austria, 1281 backcountry and off-piste avalanche accidents were reported within the winter periods of $1987 / 88-2008 / 09$. If we look at the annual avalanche backcountry and off-piste fatality average in Pfeifer et al. (2018), we notice about 20 fatalities within the past 30 years (about 11 fatalities in case of the Tyrol). More than $90 \%$ of avalanche fatalities in Austria are due accidents in the backcountry (Höller 2017).

Considering avalanche accidents in the western part of Austria (federal states Tyrol and Vorarlberg, 890 cases) on the basis of municipal strata, Figure 1 impressively shows a highly uneven spatial distribution of avalanche accidents - see also the discussion in Section 4 of this article.

From the very beginning, it has been an aim to present guidelines for backcountry skiers in order to avoid avalanche accidents (such as: Reduction Method of Munter (2013), Pfeifer (2010)).

Since 2010 the Tyrolean avalanche service is publishing special information for backcountry skiers which we call 'avalanche danger patterns' (see Mair and Nairz (2011)) such as:

\begin{tabular}{lll}
\hline $\mathrm{Nr}$ & Avalanche danger patterns & Avalanche problems \\
\hline 1 & deep persistent weak layer & persistent weak layer \\
2 & gliding snow/avalanche & gliding snow \\
3 & rain on snow & \\
4 & cold following warm/warm following cold & new snow \\
5 & snowfall after long period of cold & wind-drifted snow \\
6 & cold, loose snow and wind & \\
7 & snow-poor zones in snow-rich surrounding & \\
8 & buried surface hoar / surface hoar blanketed with snow & \\
9 & buried graupel / graupel blanketed with snow & wet snow \\
10 & springtime scenario & \\
\hline
\end{tabular}

Table 1 Avalanche danger patterns according to Mair an Nairz (2011) on the left and avalanche problems used by the majority of the avalanche warning services on the right 511 .

Recently, some other avalanche service centers in Austria, Italy and Bavaria are publishing five avalanche problems as listed in the right column of Table

However, Mair and Nairz (and others) did not give any empirical evidence for the effects of their danger patterns on avalanche danger.

As a result of a descriptive analysis of avalanche data, Höller states in (Höller 2012) that the majority of recreational avalanche accidents occurs in only a few (short) periods within the winter seasons. Höller (2009) indicated that avalanche cycles are characterized by 'continuous increase of snow depth over a period of at least three days' and 'northwesterly oriented frontal zones'. Hoi emphasizes in his discussion (Hoi 2012) that there are exemplary time 
periods of avalanche events ('Lawinenzeit') due to special weather conditions. But he did not give a more detailed description of these patterns.

Generally, a comprehensive statistical exploration of periodically occurring effects in this context is missing (but possibly see Pfeifer et al. (2018)).

Techel, Zweifel and Winkler (2014) note that 'weekend', weather (and avalanche conditions) influence the number of recreationists while the 'odds' to be involved in a severe avalanche accident did not depend on weekends or weather conditions.

In (Pfeifer 2010), the probability model suggests that touring/weather conditions and weekdays have an (although not significant) effect on avalanche accident numbers.

In 2002, Harvey and Signorell describe avalanche clusters dependent on weather conditions such as snow/wind/temperature according to:

- accident-days after new snow, strong winds with weak snow pack layers

- days (20\%) with an increase of temperature without new snow and strong winds

are characterizing avalanche clusters.

In (Harvey 2008), the author highlights 4 avalanche problems of increased risk:

- new snow (situation)

- wind-driven snow

- old snow and

- wet snow

In this contribution we are going to analyse such kind of patterns in relation to backcountry avalanche accidents. Avalanche experts expect that at least new snow has a significant effect on backcountry avalanche accidents (see Höller (2009); Höller (2012)). At first (which is among others a basis for further research of avalanche problems), we are investigating the effects of temperature, rain, snow and wind on the probabilities of avalanche accidents. It is precisely in this respect, however, that comprehensive statistical results are missing.

In Section 2, we give a short description of the avalanche and weather data which are needed running the statistical models described in Section 3. Section 4 gives a descriptive analysis of the data and the results of the models introduced in Section 3. Section 5 is summarizing the results so far and gives some final conclusions.

\section{Data}

- Number of daily backcountry (and off-piste) avalanche accidents in the western part of Austria (federal states Tyrol and Vorarlberg) within the winter periods 1987/88-2008/09 stratified by municipal areas; see Amt der Tiroler Landesregierung, 1994-2010 and Kuratorium für alpine Sicherheit 
1973-2011.The total number of accidents which are taken into account: 885. In order to check the reliability of the accident data, we made a crosscheck with those reported in the annual report of the Kuratorium für Alpine Sicherheit (due to the avalanche reports of the Austrian Alpine Police).

- Homogenized daily precipitation totals $(\mathrm{mm})$ and temperature means $\left({ }^{\circ} \mathrm{C}\right)$ from 18 weather stations in Tyrol and Vorarlberg since 1987; see Auer et al., 2010. Usually historic weather station data are affected by inhomogeneities due to e.g. station relocation, instrumentation changes or changes in observing times. However, such inhomogeneities in time series have been detected and adjusted (homogenization) in order to get an useful database over time using methods described in (Auer et al. 2010).

- Wind data: In a first attempt we had a focus on wind data from the ERA5 (former: ERA-Interim) Archive at the European Centre for Medium-Range Weather Forecasts (ECMWF) which is a reanalysis of the global atmosphere covering the period from 1979 up to now and also future periods (C3S 2017). In particular, we calculated wind strength and direction for ERA5-rectangles without getting reliable results. See Figure 2, (Lang et al. 2019) and the discussion in Section 4.

As an alternative we use 10 metre wind data (velocity $(\mathrm{m} / \mathrm{s})$, wind direction) of weather stations located on Austrian avalanche accident hot spots (Sölden, St. Anton am Arlberg, Lech). - in particular daily 07.00 LMT(Local Mean Time), 14.00 LMT and 19.00 LMT wind data.

- Digital elevation data/model: Considering the backcountry terrain (sea level $\geq 1500 \mathrm{~m}, 25^{\circ} \leq$ slope $\leq 45^{\circ}$ ), we estimate the aspect distribution of the ground surface for each municipality using a digital elevation model (DEM; available from the open source database 'Google Earth Engine' at a $30 \mathrm{~m}$ resolution). With this information in mind and considering the direction and velocity of the wind, we are able to calculate the daily mean wind load for each municipality, see Conlan and Jamieson (2016) page 245.

\section{Models}

Using a spatial kriging model we are computing mean precipitation and mean temperature every day for about 300 municipal areas separately. We did these calculations using the kriging functions of the $\mathrm{R}$ package geoR, see e.g. Diggle and Ribeiro (2007).

As a result of this, we are able to calculate the mean snow water equivalent (SWE) and rain $(\mathrm{mm})$ in alpine regions (e.g. sea level $\geq 1500 \mathrm{~m}$ ) within each municipality considering the average snow line (e.g. defined by zero-degree line) and the distribution of alpine region levels in the corresponding municipal area.

As mentioned in the Section above, hourly wind direction (degree) and wind velocity data are available as a $30 \mathrm{~km}$ grid data set over the western part of Austria. After aggregating them to daily data calculating the mean 
(alternative: the past 3 days), they are superimposed on municipal polygon data using weights according to the area of the municipalities in relation to the grids. As a result, we are able to use daily (or the past 3 day) wind direction and velocity data on a municipal level.

Finally we are analyzing the effects of snow, rain, temperature and wind data on the number of observed daily avalanche accidents within each municipal area. For this purpose we employ a hurdle count model which takes into account that avalanche counts are expected to be rather rare:

The observations $y_{i}$ of the hurdle model are assumed to come from a mixture that is zero with probability $1-p$ in the first component (logistic part) and a truncated Poisson model in the second component (loglinear part):

$$
\mathbf{p}\left(y_{i}\right)=\left\{\begin{array}{rll}
1-p & : & y_{i}=0 \\
\frac{p \exp (-\lambda) \lambda^{y_{i}}}{(1-\exp (-\lambda)) y_{i} !} & : & y_{i}>0
\end{array}\right.
$$

In order to define the covariate effects on the observations we use the link functions of the logistic and the loglinear model:

$$
\log (\lambda)=\mathbf{B} \beta \quad \operatorname{logit}(\mathbf{p})=\mathbf{G} \gamma
$$

The fitting of this model is done using the hurdle ( ) function which is part of the R package pscl, see Zeileis et al., 2008.

Finally, we introduce the variable weekend-holidays Yes/No as a covariate into the statistical model in order to take into account the skiers frequency in some way - see also Pfeifer (2010).

\section{Results and Discussion}

At first, the ERA 5 climate reanalysis wind data turned out not to be reasonable for the alpine region in our case; for illustration see Figure 2 where wind data in case of the municipality St. Anton am Arlberg are compared with weather station data (Galzig) in 2009 showing poor correlation and considerable differences on the scale.

Table 2 reports the descriptive analysis of the variables SWE (mm), rain (mm) and temperature $1800 \mathrm{~m}$ above sea level (temp $1800,{ }^{\circ} \mathrm{C}$ ) dependent on the number of daily avalanche accidents. Beside the explanatory variables snow, rain (and wind, $\mathrm{m} / \mathrm{s}$ ), which are the daily values, we are considering the running average over the last 3 days denoted by SWE3 and rain3.

In the case of SWE (mean: 1.89, max: 84.51) we observe no considerable increase/decrease if counts are $>0$, which is, however, in contrast to the increase of SWE3 if counts are $>0$ (count $0: 1.91,1: 3.17,2: 3.46)$. In case of rain (mean: 0.49, max: 88.31) we note a decrease (count 0: 0.49, 1: 0.06, 2 : 0.03 ) similarly to the profile (dependent of the number of avalanche accidents) of the variable rain3 (count 0: 0.49, 1: 0.13, 2: 0.02). Maybe, let us mention that the smaller standard deviations (sd) and maxima of SWE3 and rain3 in relation to SWE and rain are due to smoothing effects of the running mean. 
In the case of temp1800 (mean: -4.33 , min: -21.08 , max: 12.91) we note a decrease of the variable in a similar way (count $0:-4.33,1:-5.19,2:-4.51$ ).

Figure 3-5 show boxplots additionally reporting cases with more than 2 avalanche accidents per day. In addition, we take notice of the highly positively skewed distributions.

Further on, Table 3 reports the descriptive results of the variable wind $(\mathrm{m} / \mathrm{s})$, more precisely the daily mean wind data, dependent on the number of daily avalanche accidents. Instead of using reanalysis data, we use wind data of the weather stations Galzig, Warth and Obergurgl within the municipalities St. Anton am Arlberg, Lech and Sölden which turned out to be the hot spots of avalanche accidents, see Figure 1 (St. Anton am Arlberg (66 accidents), Lech (56), Sölden (73)). We notice an increase of wind in case of St. Anton am Arlberg (count 0: 4.38, 1: 6.05, 2: 7.78) and Lech (count 0: 1.58, 1: 1.79,2: 1.72 ) if counts are $>0$. In the case of Sölden we are not able to identify a notable increase or decrease. Figure $6-8$ show boxplots of the variable wind in case of St. Anton am Arlberg, Lech and Sölden for illustration.

Table 4 shows the results of our modelling approach using the variables snow, rain and temperature assuming that only the logistic part of the models $(\gamma)$ is of interest for us. Beside the effects and p-values the log likelihoods of the logit and hurdle model are reported. As we can see, SWE3 has a positive significant influence $(0.065)$ on avalanche accident counts, see also the boxplot in Figure 3 for illustration. Further on, we notice that rain (actual value (effect: -0.531) and mean of the last 3 days (-0.529)) has a significant negative effect on avalanche counts.

The mean temperature at 1800 meter above sea level (temp1800) turns out to have a negative effect $(-0.030)$ on avalanche counts. See also Figure 4 and 5 in order to get a visual impression of the dependencies in case of rain and temperature.

The effects in Table 4 are controlled by the variable weekend/holidays (by itself significant; in contradiction to Zweifel and Winkler (2014)) - in order to take the larger frequency of backcountry skiers into account.

Additionally, we are considering the model SWE3 with the interaction term temp1800:SWE3 (on the restricted database) which turns out, although small, to be significant. As a result of this (interaction term negative), the effect of snow on avalanche counts seems to become less important if the temperature is higher.

Instead of using climate reanalysis wind data, we had a focus on data at avalanche hot spots in Austria (St. Anton, Lech and Sölden) as described above. In particular, we are considering daily average wind velocity data and the west/north wind component of the $07 \mathrm{~h}, 14 \mathrm{~h}, 19 \mathrm{~h}$ LMT values. Modelling results of Table 5 show positive effects for daily wind velocity data (total) at least in case of Galzig/St. Anton $(0.318, p=0)$ and Warth/Lech $(0.334,0.038)$. Considering the west/north wind components of the $7 \mathrm{~h}, 14 \mathrm{~h}$ and $19 \mathrm{~h}$ wind data we observe positive significant results in case of St. Anton am Arlberg (7h: 0.205, 14h: 0.201, 19h: 0.19) and Lech $(0.409,0.289,0.290)$ if we look at the west wind component. 


\begin{tabular}{lrrrrrr}
\hline vars & group & $\mathrm{n}$ & mean & $\mathrm{sd}$ & min & max \\
\hline SWE & 0 & 967734 & 1.89 & 4.55 & 0 & 84.51 \\
SWE3 & 0 & 949701 & 1.91 & 3.39 & 0 & 50.7 \\
rain & 0 & 967734 & 0.49 & 2.2 & 0 & 88.31 \\
rain3 & 0 & 949701 & 0.49 & 1.49 & 0 & 46.68 \\
temp1800 & 0 & 967734 & -4.33 & 5.24 & -21.08 & 12.91 \\
SWE & 1 & 753 & 1.77 & 4.25 & 0 & 41.1 \\
SWE3 & 1 & 731 & 3.17 & 3.88 & 0 & 28.34 \\
rain & 1 & 753 & 0.06 & 0.41 & 0 & 6.37 \\
rain3 & 1 & 731 & 0.13 & 0.56 & 0 & 5.58 \\
temp1800 & 1 & 753 & -5.19 & 4.81 & -18.04 & 9.75 \\
SWE & 2 & 23 & 1.83 & 3.73 & 0 & 15.67 \\
SWE3 & 2 & 22 & 3.46 & 3.35 & 0 & 13.21 \\
rain & 2 & 23 & 0.03 & 0.09 & 0 & 0.3 \\
rain3 & 2 & 22 & 0.02 & 0.06 & 0 & 0.23 \\
temp1800 & 2 & 23 & -4.51 & 4.65 & -12.38 & 7.92 \\
\hline
\end{tabular}

Table 2 Summary of precipitation and temperature variables grouped by daily avalanche accident numbers up to 2 accidents per day

\begin{tabular}{lrrrrrr}
\hline municipality & group & $\mathrm{n}$ & mean & sd & min & max \\
\hline St. Anton a. A. & 0 & 2334 & 4.38 & 1.90 & 0.77 & 13.67 \\
& 1 & 40 & 6.05 & 2.90 & 1.03 & 12.93 \\
Lech & 2 & 5 & 7.78 & 2.52 & 3.87 & 10.37 \\
& 0 & 3276 & 1.58 & 0.70 & 0 & 6.20 \\
Sölden & 1 & 48 & 1.79 & 0.69 & 0.60 & 3.67 \\
& 2 & 4 & 1.72 & 0.43 & 1.20 & 2.17 \\
& 0 & 3267 & 1.58 & 0.88 & 0.13 & 6.37 \\
& 1 & 60 & 1.58 & 0.83 & 0.53 & 5.53 \\
& 2 & 1 & 1.03 & NA & 1.03 & 1.03 \\
\hline
\end{tabular}

Table 3 Summary of wind variable grouped by daily avalanche accident numbers up to 2 accidents per day

\begin{tabular}{lrrrr}
\hline model & effect & p-value & Log-lik logit & Log-lik hurdle \\
\hline SWE & -0.008 & 0.364 & -6275 & -6396 \\
SWE3 & 0.065 & 0.0 & -6056 & -6172 \\
temp1800 & -0.030 & 0.0 & -6265 & -6387 \\
rain & -0.531 & 0.0 & -6237 & -6357 \\
rain3 & -0.529 & 0.0 & -6048 & -6163 \\
weekend & 0.708 & 0.0 & -6451 & -6579 \\
\hline temp1800:SWE3* & -0.008 & 0.001 & -6051 & -6166 \\
\hline
\end{tabular}

Table 4 Summary of hurdle models for the avalanche accidents count data, effects of snow (SWE), rain, temperature etc. on avalanche accident counts reporting effect and p-value of the logistic part * with SWE3 as covariate (not sign.)

In the case of Sölden we observe no meaningful significant results.

If we use the direction and velocity information of $07 \mathrm{~h}, 14 \mathrm{~h}$ and $19 \mathrm{~h}$ wind data we are able to compute the mean wind load according to Conlan and Jamieson (2016). However, there are only noteworthy results for St. Anton am Arlberg: 7h (effect: 7.564, p-value: 0.0), 14h (4.351, 0.0) 19h( 5.518, 0).

Further on, we had a look on the snow/rain pattern (rain on new snow; danger pattern no. 3, Mair and Nairz 2011) without finding significant results. 


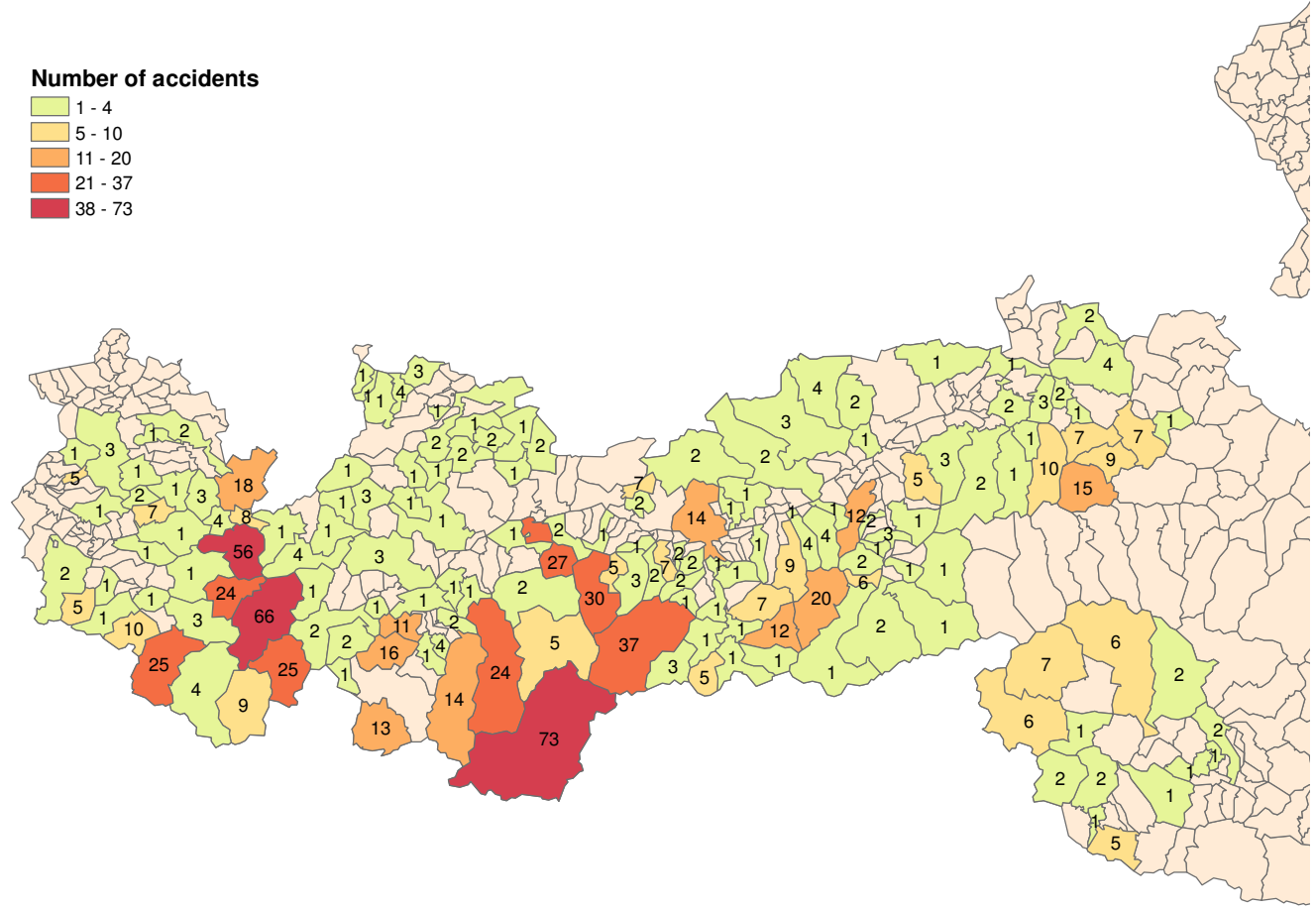

Fig. 1 Spatial distribution of avalanche accidents in the western part of Austria within the winter periods $1987 / 88$ and 2008/09

We also tried to model the new snow and wind situation according to avalanche danger pattern no. 6, see also the avalanche patterns in Harvey and Signorell (2002) and Harvey (2008), without finding a model with a coherent result. 


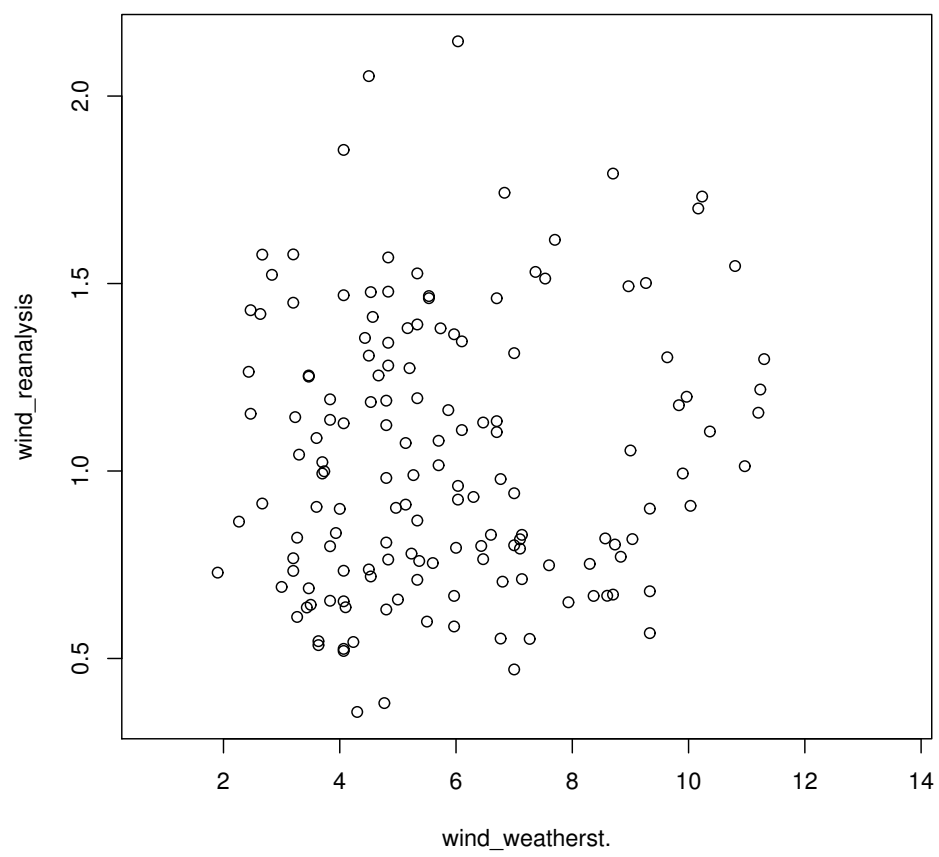

Fig. 2 ERA 5 climate reanalysis wind data (St. Anton am Arlberg) in relation to weather station wind data (Galzig) in $2009-$ corr $=0.0816$

\begin{tabular}{lrrrrr}
\hline station/municip. & total & component & wind7h & wind14h & wind19h \\
\hline Galzig/St. Anton & $0.318(\mathrm{p}=0.0)$ & west & $0.205(0.0)$ & $0.201(0.0)$ & $0.190(0.0)$ \\
& & nord & $0.110(0.356)$ & $0.165(0.064)$ & $0.202(0.033)$ \\
Warth/Lech & \multirow{2}{*}{$0.334(0.038)$} & west & $0.409(0.0)$ & $0.289(0.020)$ & $0.290(0.020)$ \\
& & nord & $0.063(0.803)$ & $-0.142(0.344)$ & $-0.539(0.001)$ \\
Oberg./Sölden & \multirow{2}{*}{$0.034(0.821)$} & west & $-0.173(0.184)$ & $-0.077(0.523)$ & $0.153(0.264)$ \\
& & nord & $0.132(0.277)$ & $-0.013(0.909)$ & $-0.089(0.458)$ \\
\hline
\end{tabular}

Table 5 Summary of hurdle models for the avalanche accidents count data, effects of wind direction and velocity on avalanche accident counts and p-value of the logistic part

Focusing a 'spring scenario' such as in Harvey (2008) and the avalanche danger pattern no. 10 by restricting the database to the months March, April and May, we observe 2 models: wet snow (defined by temp1800>0), which turned out to be not significant and the difference of daily mean temp1800 (effect: 0.08628, p-value: 0.002; to some extent in accordance with the second avalanche cluster in Harvey and Signorell (2002)). 


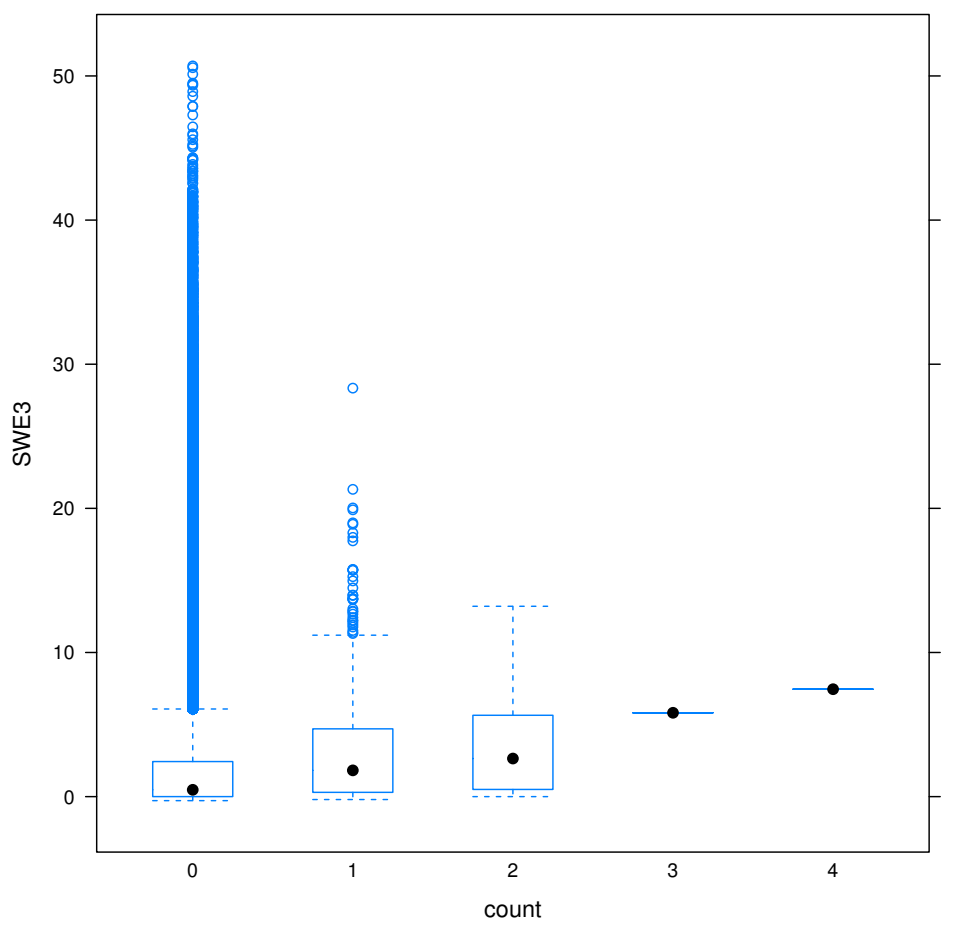

Fig. 3 Mean new snow water equivalent in the last 3 days (SWE3) in relation to the number of daily avalanches accidents in municipal areas

\section{Summary}

In this article, we were investigating the effects of snow, rain, temperature and wind on the number of backcountry and off-piste avalanche accidents. Our survey is located on the western part of Austria (federal states Tyrol and Vorarlberg) within the winter periods $1987 / 88-2008 / 09$. It turned out that the variable SWE3 (running average of the snow water equivalent over the past 3 days) has a significant effect on the number of avalanche accidents while temperature and rain show negative effects on avalanche accident counts. In case of investigating wind effects we used climate reanalysis data in a first attempt. We, however, noticed that this data are not reasonable for our purposes. As an alternative we looked at weather station wind data at avalanche accident hot spots in Austria. In the case of Galzig/St. Anton a. Arlberg and Warth/Lech we found significant results take note of positive effects on avalanche accident counts (positive effects of mean wind load as well if we consider St. Anton a. Arlberg).

Finally we were considering special types/patterns of weather conditions (according to the avalanche patterns/problems in Section 1): 


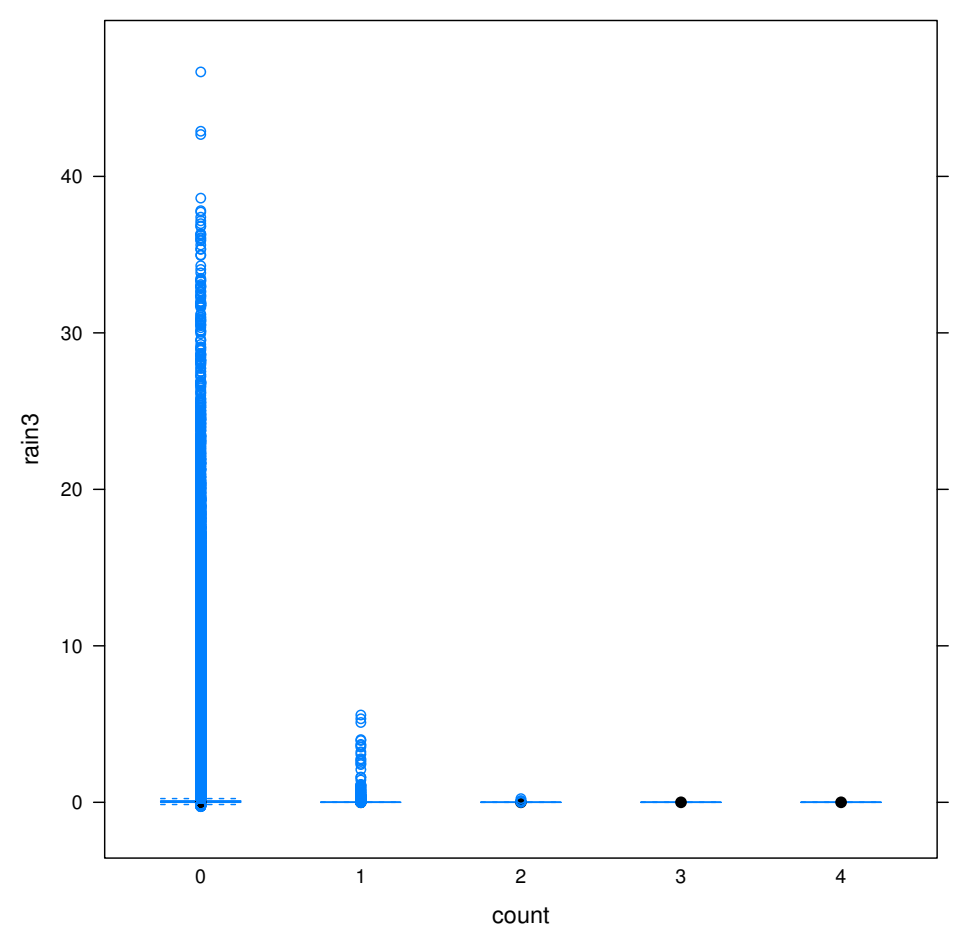

Fig. 4 Mean rain in the last 3 days in relation to the number of daily avalanche accidents in municipal areas

- avalanche danger pattern no. 3, rain on new snow (no significance)

- Models with snow-wind interaction (higher avalanche accident counts in case of new snow and wind) turned out to be not meaningful. Maybe our data base ('hot spot' municipalities) is too small for this research question.

- Spring scenario: temperature 1800 above sea level> 0 no significance; in contrast to the positive significant effect if we consider the differences of daily average temp1800 values.

In practice, we recommend for backcountry and off-piste skiers especially to be careful in case of higher values of new snow (average over 3 days). Taking this into account in the avalanche accident hot spots around St. Anton a. Arlberg and Sölden - see the 'narrow' spatial distribution of accidents (Figure 1) and fatalities (Pfeifer et al. 2018) - could significantly lower the number of accidents and fatalities in Austria. In the case of wind data we state that the results are possibly highly dependent on the location of the weather station if we take them in relation to avalanche accident counts. Thus for further research, we are looking forward to homogenized wind data according to Auer et al. (2010). 


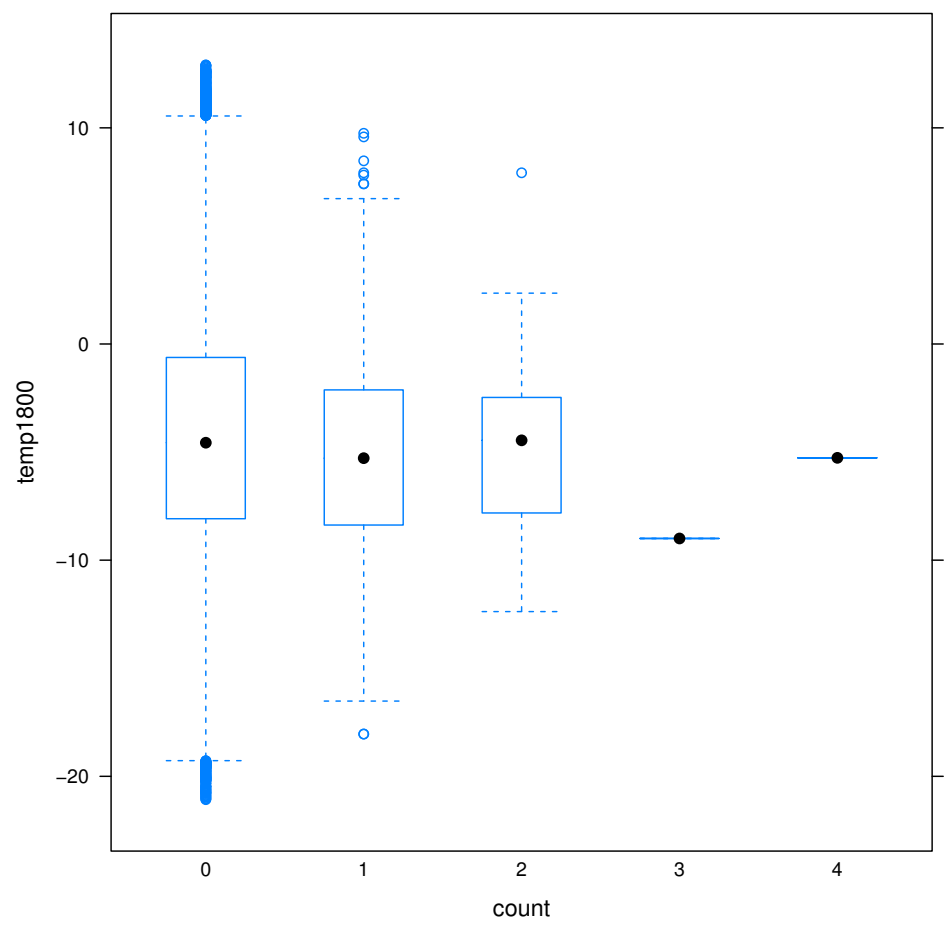

Fig. 5 Mean temperature $1800 \mathrm{~m}$ above sea level in relation to the number of daily avalanche accidents in municipal areas

\section{Conflict of interest}

The authors declare that they have no conflict of interest.

\section{Ethical statement}

All procedures relating to this article were in accordance with the ethical standards of the responsible committee on human experimentation (institutional and national) and with the Helsinki Declaration of 1975, as revised in 2000.

\section{References}

1. Amt der Tiroler Landesregierung (1994-2010) Schnee und Lawinen, Jahresberichte. Raggl, Innbruck

2. Auer I, Nemec J, Gruber C, Chimani B, Türk K (2010) HOM-START. Homogenisation of climate series on a daily basis, an application to the StartClim dataset. Klima und Energiefonds Projektbericht. Vienna 


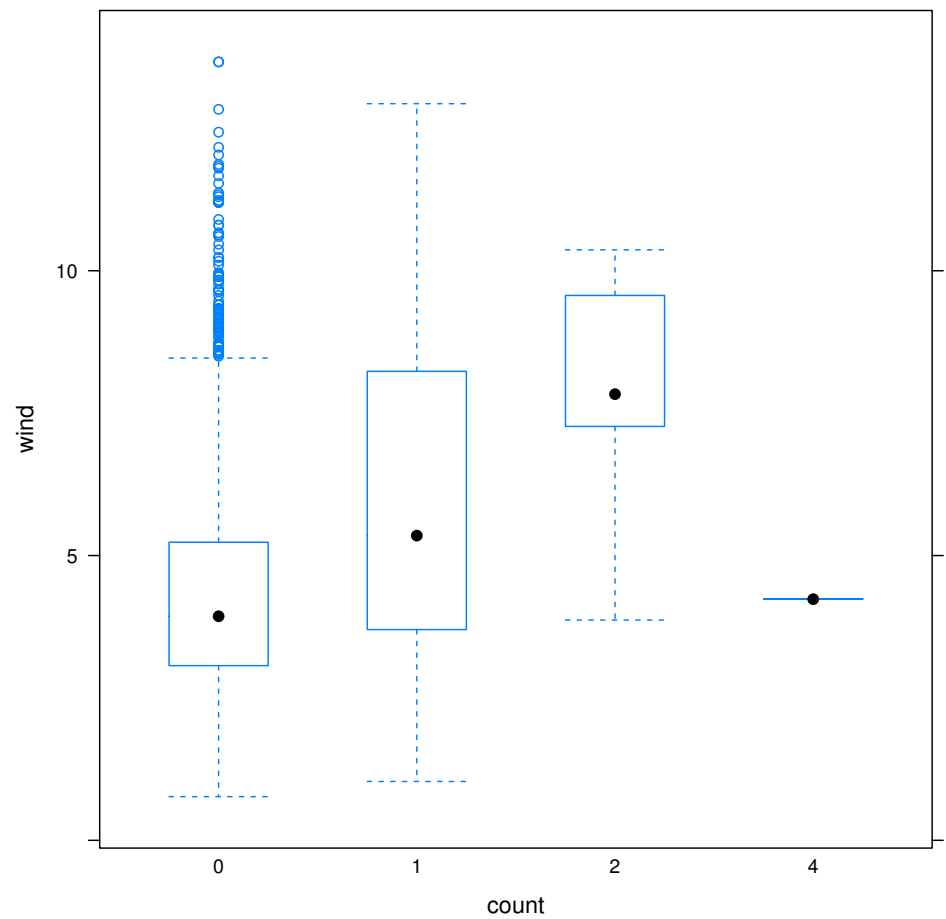

Fig. 6 Mean wind in relation to the number of daily avalanche accidents Galzig/St. Anton a. Arlberg

3. Copernicus Climate Change Service (C3S) (2017) ERA5: Fifth generation of ECMWF atmospheric reanalysis of the global climate. Copernicus Climate Change Service Climate Data Store (CDS), date of access. https://cds.climate.copernicus.eu/cdsapp

4. Conlan M, Jamieson B (2016) Naturally triggered persistent deep slab avalanches in western Canada Part I: avalanche characteristics and weather trends from weather stations. Journal of Glaciology 62:243-255

5. Diggle P, Ribeiro PJ (2007) Model-based Geostatisics. Springer, New York

6. Harvey S, Signorell C, Genswein M (2002) Avalanche accidents in back country terrain of the Swiss alps: New investigations of a 30 year database. In: Proceedings International Snow Science Workshop 2002. Penticton, British Columbia, pp 449-455

7. Harvey S (2008) Mustererkennung in der Lawinenkunde. In: Sicherheit im Bergland. Jahrbuch des Kuratoriums für alpine Sicherheit. Innsbruck, pp 53-72

8. Hoi K (2012) Lawinenzeit. In: Bergundsteigen 1/2012, p 12

9. Höller P (2009) Avalanche cycles in Austria: an analysis of the major events in the last 50 year. Natural Hazards 48:399-424

10. Höller P (2012) The cumulation of avalanche accidents in certain periods - an analysis of backcountry events in Austria. In: Proceedings International Snow Science Workshop 2012. Anchorage, Alaska, pp 332-339

11. Höller P (2017) Avalanche accidents and fatalities in Austria since 1946/47 with special regard to tourist avalanches in the period 1981/82 to 2015/16. Cold Regions Science and Technology 144:89-95

12. Kuratorium für alpine Sicherheit (1973-2011) Sicherheit im Bergland. Jahrbücher des Kuratoriums für alpine Sicherheit. Kuratorium, Vienna. 


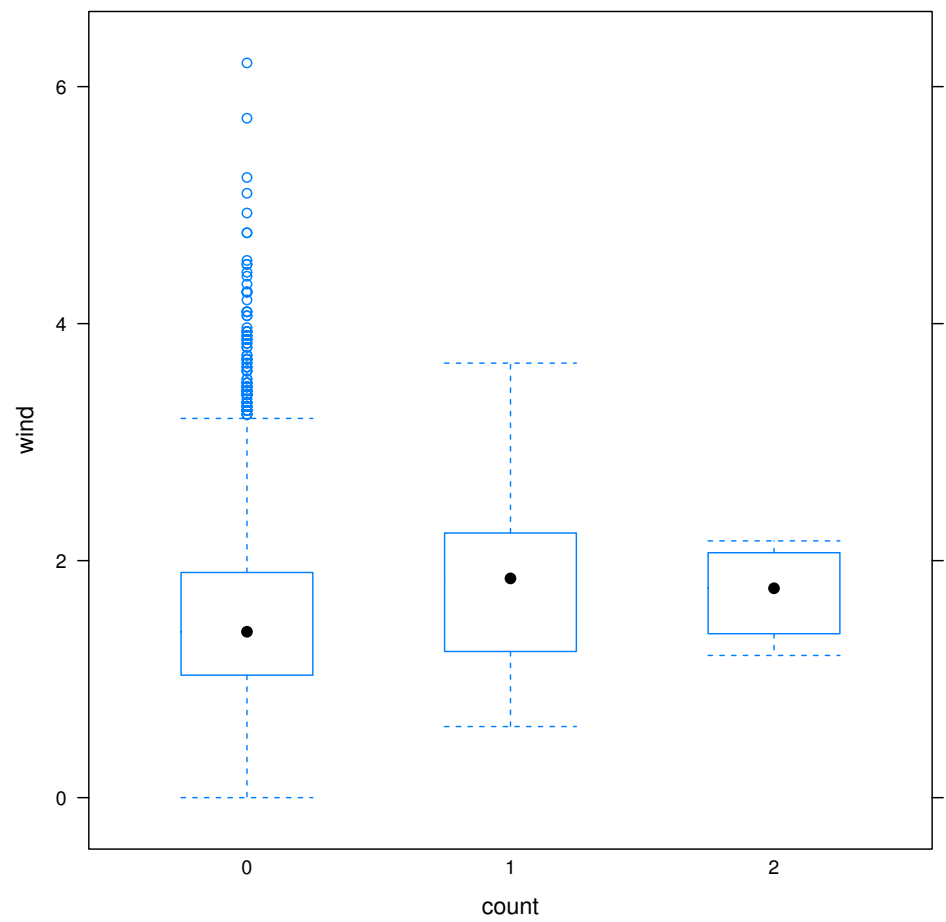

Fig. 7 Mean wind in relation to the number of daily avalanche accidents Warth/Lech

13. Lang M, Mayr G, Stauffer R, Zeileis A (2019) Bivariate Gaussian models for wind vectors in a distributional regression framework. Advances in Statistical Climatology, Meteorology and Oceanography 5:115-132

14. Mair R, Nairz P (2011) Lawine. Die entscheidenden 10 Gefahrenmuster erkennen. Praxis-Handbuch. Tyrolia, Innsbruck

15. Munter W (2014) 3x3 Lawinen. Risikomanagement im Wintersport. Tappeiner Verlag, Lana

16. Pfeifer C (2010) On probabilities of avalanches triggered by alpine skiers. An empirically driven decision strategy for backcountry skiers based on these probabilities. Natural Hazards 48:425-438

17. Pfeifer C, Höller P, Zeileis A (2018). Spatial and temporal analysis of fatal off-piste and backcountry avalanche accidents in Austria with a comparison of results in Switzerland, France, Italy and the US. Natural Hazards and Earth System Science 18:571-582

18. Techel F, Zweifel B, Winkler K, Baur R (2014) Patterns of recreational backcountry usage in Switzerland - analyzing data from social media mountaineering networks and avalanche statistics. In: Proceedings International Snow Science Workshop 2014. Banff, Cananda, pp $1148-1152$

19. Techel F, Jarry F, Kronthaler G, Mitterer S, Nairz P, Pavsek M, Valt M, Darms G (2016) Avalanche fatalities in the European Alps: long-term trends and statistics. Geographica Helvetica 71:147-169

20. Zeileis A, Kleiber C, Jackman S (2008) Regression Models for Count Data in R. Journal of Statistical Sofware 27(8)

21. Zweifel B, Raez A, Stucki T (2006) Avalanche Risk for recreationists in backcountry and off-piste area: surveying methods and pilot study at Davos. In: Proceedings International Snow Science Workshop 2006. Telluride, Colorado, pp 733-741 


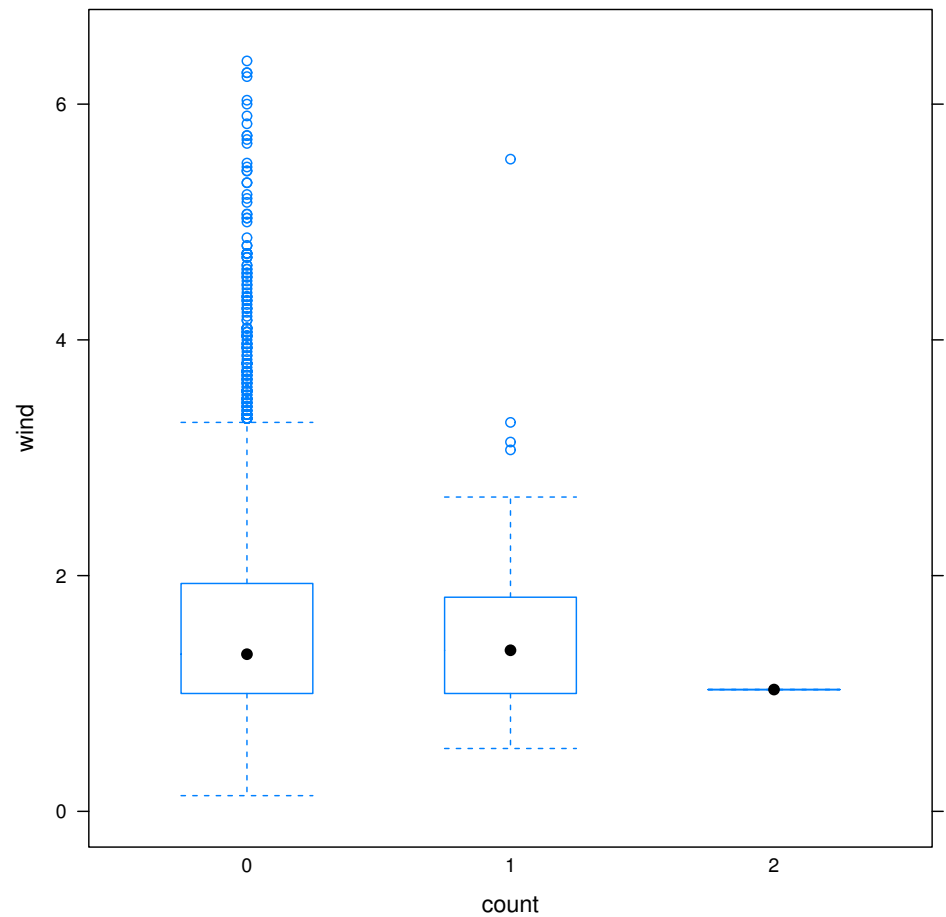

Fig. 8 Mean wind in relation to the number of daily avalanche accidents Obergurgl/Sölden 